\title{
Analysis of Equal Channel Angular Extrusion by Upper Bound Method and Rigid Block Model
}

\author{
Alexander M. Laptev $v^{\mathrm{a}}$,Alexander V. Perig ${ }^{\mathrm{b} *}$, Olena Yu. Vyal \\ a Department of Mechanical Engineering, Donbass State Engineering Academy, \\ Shkadinova, 72, 84313, Kramatorsk - Ukraine \\ ${ }^{\mathrm{b}}$ Department of Industrial Automation, Donbass State Engineering Academy, \\ Shkadinova, 72, 84313, Kramatorsk - Ukraine
}

Received: April 4, 2013; Revised: October 16, 2013

\begin{abstract}
In present paper the Equal Channel Angular Extrusion (ECAE) through a rectangular die was firstly physically simulated using plasticine and then theoretically analyzed by upper bound method. Physical simulation was used to identify the deformation zone and as a background for the following theoretical ECAE analysis by rigid block model. The plane strain deformation mode and ideal plasticity of an extruded material were assumed. The dependencies of ECAE pressure, accumulated shear and dimension of a "dead zone" upon friction factor were analytically determined. The rise in ECAE pressure, accumulated shear and size of a "dead zone" with the increase in friction was predicted. The obtained results were compared with the slip line based solution and a good agreement between them was found. Finally the results of upper bound analysis were discussed together with the results of experimental investigations and finite element analysis of ECAE mechanics published elsewhere.
\end{abstract}

Keywords: ECAE, physical modeling, upper bound analysis, rigid block model, slip line analysis

\section{Introduction}

The Equal Channel Angular Extrusion (ECAE) is a well known method for production of bulk materials with ultra fine grained structure ${ }^{1-4}$. Despite the simple design of ECAE tool, the homogeneity of material flow, needed pressure and resulting strains are strongly influenced by a number of process parameters like tool geometry, external friction, rheology of extruded material etc. Therefore the mechanics of ECAE attracts attention of many researchers and was investigated by both theoretical and experimental means ${ }^{5-9}$. The theoretical contributions have been focused on application of the Slip Line Theory ${ }^{10}$, Upper Bound Analysis ${ }^{5,11-13}$, Finite Difference Analysis ${ }^{9}$ and Finite Element Modeling ${ }^{6,14,15}$. Though ECAE was intensively analyzed by these methods, development of a simple engineering approach for estimation of processing characteristics would be beneficial for ECAE practice. In the present paper we applied for this aim a version of upper bound analysis based on the rigid block model developed by W. Johnson and H. Kudo ${ }^{16}$. The analysis has been carried out for a classical ECAE rectangular die with a sharp outer corner. The influence of friction on the appearance and dimensions of a dead zone, ECAE pressure and resulting shear was highlighted. The obtained results have been compared with the slip line solution modified by authors and discussed together with experimental data and results of finite element modeling available in literature. The appearance of a dead zone was confirmed by simple visualization experiments with plasticine as modeling material. We believe that the developed theoretical and

*e-mail: olexander.perig@gmail.com experimental approaches can be successfully used in the future for the analysis of ECAE mechanics, when using more complex die geometry including nonrectangular intersections of die channels, rounded corners etc.

\section{Physical Modeling}

The upper bound analysis usually started with identification of so called "dead zones", where material does not flow and is not subjected to deformation ${ }^{16,17}$. The appearance of a dead zone in the sharp die corner was observed by Rosochowski and Olejnik during modeling ECAE by wax ${ }^{8}$. However the identification of zones where deformation starts and finishes is also a matter of importance, especially for upper bound analysis based on the rigid block model. For this aim we used a simple visualization technique and plasticine as a modeling material. The prototype of an ECAE die was manufactured from a piece of wood with two side walls made from Plexiglas ${ }^{\circledR}$. The transparent Plexiglas walls allowed in-situ observation of plasticine flow during angular extrusion. The width of the die channel was $35.4 \mathrm{~mm}$ and channel intersection angle was $90^{\circ}$ as it is schematically presented in Figure 1. Three types of plasticine samples were used in experiments. First sample was made from several vertical layers of different color plasticine (Figure 1a). The second sample was manufactured by homogeneous strewing of plasticine with fine sawdust of wood, which served as markers (Figure 1b). The third sample was produced by insertion of small plasticine cylinders into a plasticine matrix of different color. The set of small cylinders forms a kind of grid, as shown in Figure 1c. 
The samples were angular extruded and photographed through the transparent die wall. The typical views of samples are shown in Figure 1. In all cases the dead zone in the die corner is clearly defined. Intensive plastic deformation starts in the inlet channel when plasticine crosses the line OA and finishes in the outlet channel after the material crosses the line OB. Figure 1c also shows that strain distribution during ECAE can be highly inhomogeneous. Of course, the rheological behavior of plasticine is viscous in contrast to the plastic behavior of metals at typical ECAE conditions. At the same time, the peculiarities of metals flow during plastic forming can be quantitatively simulated using plasticine as a simple modeling material ${ }^{18}$.

\section{Upper Bound Analysis}

Rigid block analysis is a version of upper bound analysis based on a virtual velocity field of discontinuous manner ${ }^{16}$. A real metal forming process (frequently extrusion) is usually approximated as a plane strain scheme of deformation of ideally plastic material. The sample cross-section is partitioned into several rigid blocks, which can slide along contact surfaces over each other. Such kind of deformation results in a discontinuous velocity field. The next steps of the analysis are the construction of velocities hodograph and composition of an equation describing the balance of external power and its internal dissipation on contact surfaces of adjacent rigid blocks and due to friction. The working pressure is estimated by solving of this equation. Because the partitioning of sample into rigid blocks can be done in different manners, the optimization of obtained solution is desirable. Corresponding to the main concept of the upper bound analysis the best approximation of a real working pressure by a virtual one corresponds to a minimal value of calculated virtual pressure. The results of minimization of virtual modeled working pressure can be used for prediction of some kinematical parameters of a metal forming process, for instance, for evaluation of dead zone size and shear during ECAE. Application of this methodology to the investigation of ECAE is described below.

The plane cross-section of an ECAE billet was symmetrically partitioned into 6 rigid blocks, as shown in Figure $2 \mathrm{a}$. The symmetry of partitioning has been resulted from an equal friction in the die channels. The appearance of a symmetrical triangular dead zone CED, with a height of $h$, was assumed. The used partitioning was carried out in concordance with the observation of deformation zones as described in the previous section. Blocks 1 and 3 correspond to the area of moderate deformation. Block 2 corresponds to the area of intensive deformation. Block 4 reflects the dead zone. Blocks 5 and 6 represent the inlet and outlet channels. The hodograph of velocities of rigid blocks corresponding to the used partitioning scheme is shown in Figure 2b. Here one subscript denotes a block number and double subscript denote a contact surface between two blocks. The velocities of blocks 5 and 6 are the same as the velocities of blocks 1 and 3 .

The balance of external power and its internal dissipation during plastic deformation is expressed by the following basic equation

$$
W_{e}=W_{i}=W_{d}+W_{f r}
$$

here $W_{e}$ and $W_{i}$ are external power and its internal dissipation during plastic deformation, $W_{d}$ is power dissipation due to blocks mutual sliding and $W_{f r}$ is power dissipation due to external friction. The frictional behavior of material in the present paper is defined by Tresca friction law as $\tau_{f}=m \bullet k$, where $0 \leq m \leq 1$ is a friction factor and $k$ is a shear strength of an extruded material, which is related to the flow stress $\sigma_{s}$ as $k=\sigma_{s} / \sqrt{3}$. At this point of analysis we will not consider the friction in the inlet and outlet channels $\mathrm{OO}_{1} \mathrm{~A}_{1} \mathrm{~A}$ and $\mathrm{OO}_{2} \mathrm{~B}_{1} \mathrm{~B}$. Taking into account that the shear stress on the sliding surfaces of rigid blocks is equal to the shear strength $k$ and assuming ideal plasticity (no strain-hardening) of extruded material, we can rewrite the Equation 1 as follows

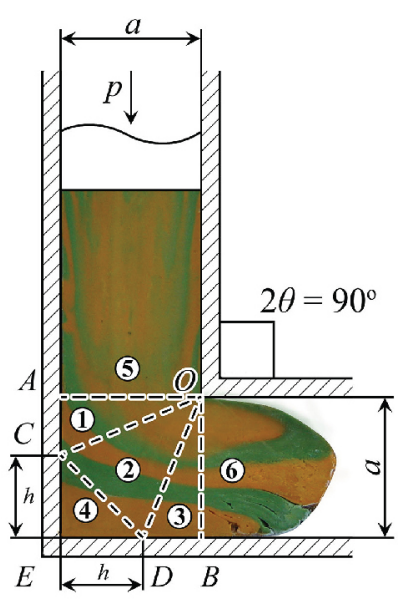

(a)

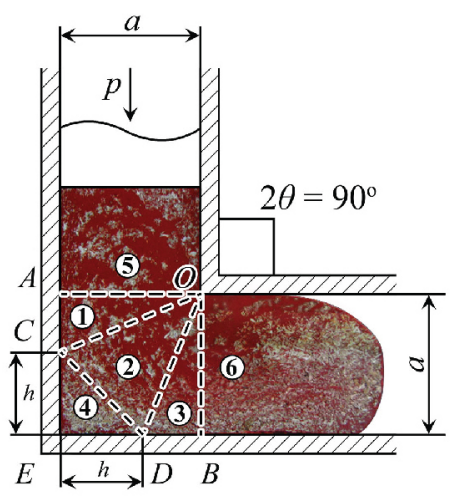

(b)

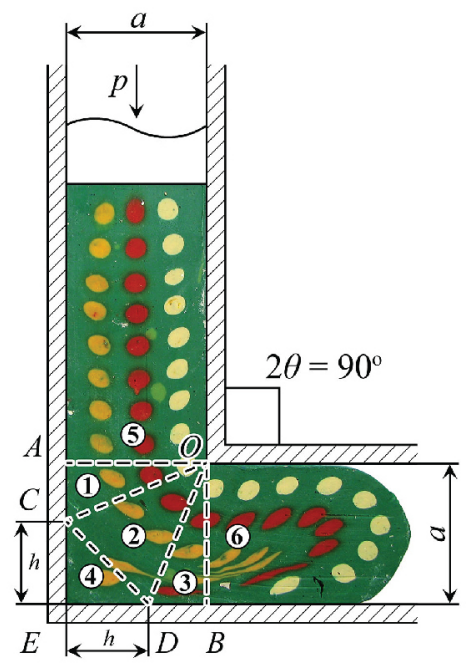

(c)

Figure 1. Physical simulation of material flow during ECAE using plasticine: layered sample (a), marker techniques (b), and gridline technique (c). 


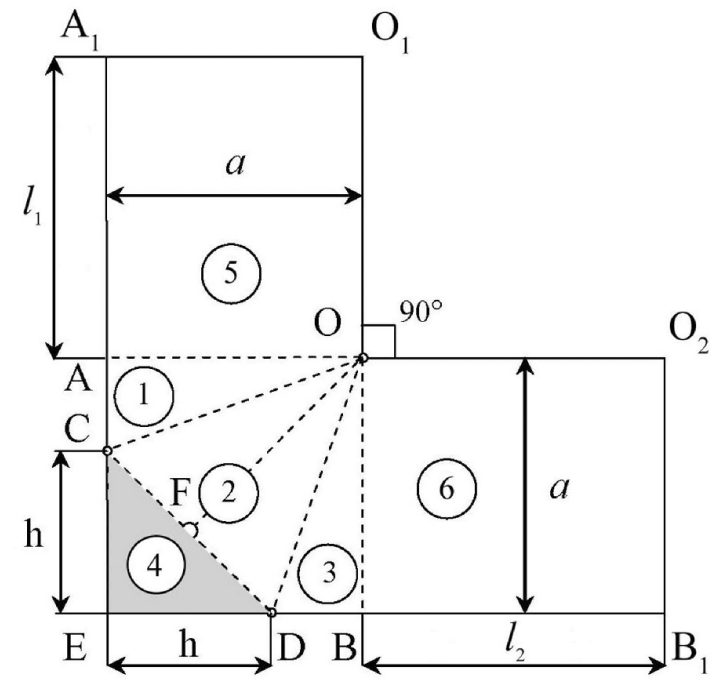

(a)

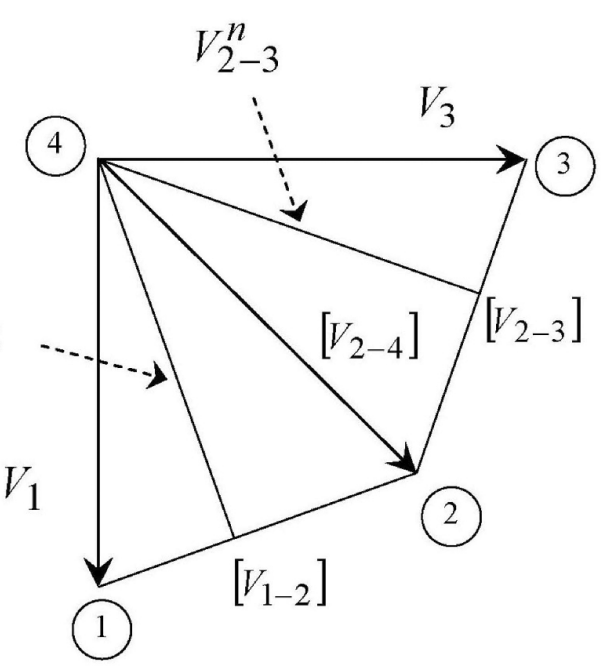

(b)

Figure 2. Partitioning of ECAE sample into rigid blocks (a) and corresponding velocities hodograph (b).

$$
\begin{aligned}
& p \cdot a \cdot V_{1}=k \cdot\left(l_{1-2} \cdot\left[V_{1-2}\right]+l_{2-3} \cdot\left[V_{2-3}\right]+l_{2-4} \cdot\left[V_{2-4}\right]\right)+ \\
& +m k \cdot\left(l_{A C} \cdot V_{1}+l_{D B} \cdot V_{3}\right)
\end{aligned}
$$

where $p$ is ECAE pressure, $a$ is width of channels, $V_{i}$ is velocity of block $i,\left[V_{i-j}\right]$ is relative sliding velocity of blocks $i$ and $j, l_{i-j}$ is length of common side of two blocks $i$ and $j$, $l_{A C}=l_{D B}$ are lengths of sides of blocks 1 and 3 contacting ECAE die. Due to the constancy of material volume $V_{1}=V_{3}$.

The terms in Equation 2 were expressed as functions of the velocity $V_{1}$ and the relative length of the dead zone $x=$ $h / a$ (Figure 2). After substitution of obtained relationships in Equation 2 and algebraic transformation, the following formula for calculation of relative ECAE pressure was derived

$$
p / 2 k=1+x^{2} /(2-x)+m(1-x) .
$$

The dependencies of relative ECAE pressure $p / 2 k$ on relative height of the dead zone $x$ at different values of friction factor $m$ are plotted in graphical form in Figure 3.

The each curve in Figure 3 has a minimum at certain value of $x$. In accordance with the upper bound theory the minimum of $p / 2 k$ corresponds to the best approximation of real working pressure by upper bound one. The values of $x$, at which the minimum is achieved, were found from the well known extremum condition $d(p / 2 k) / d x=0$ and Equation 3 . These values can be determined by the Formula 4

$x=h / a=2-2 / \sqrt{1+m}$.

The dependence of upper bound estimation of relative ECAE pressure upon the friction factor calculated by ( 3 and 4 ) is presented in Figure 4a. As expected, pressure grows with the increase in friction factor. When friction factor reaches its maximal value of 1.0, the increase in relative pressure is about $65 \%$.

As mentioned above, the main goal of ECAE technique is grain refinement. Therefore the estimation of resulting

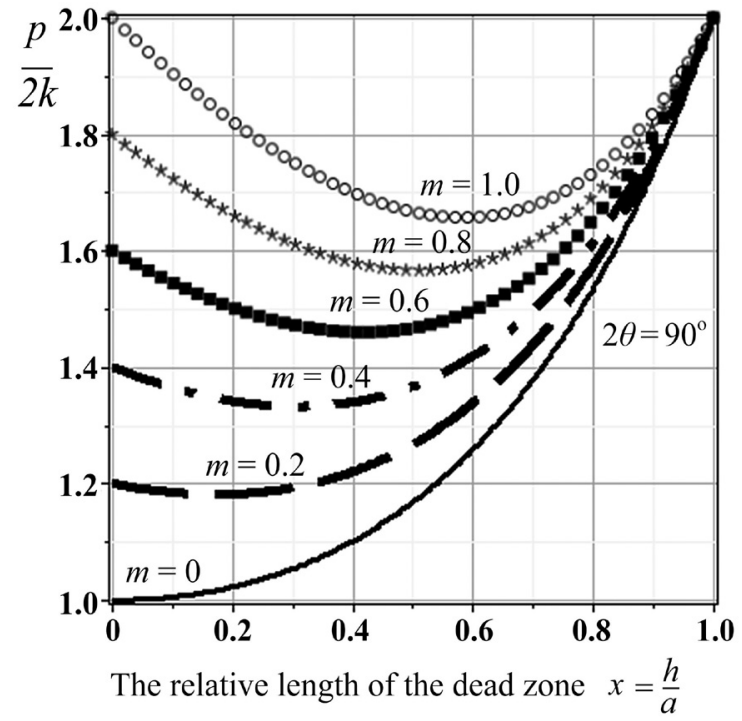

Figure 3. Relative ECAE pressure $p / 2 k$, calculated by Formula 3 at different values of friction factor $m$.

plastic shear during ECAE is a matter of special importance. The total ECAE shear $\gamma_{S}$ is the sum of the shears on the lines of discontinuities of velocity $l_{1-2}$ and $l_{2-3}$ (Figure $2 \mathrm{a}$ ), i.e.

$\gamma_{S}=\gamma_{1-2}+\gamma_{2-3}$

According to upper bound analysis, plastic shear on a line $l_{i-j}$ can be calculated as ${ }^{16}$

$\gamma_{i-j}=\left[V_{i-j}\right] / V_{i-j}^{n}$

where $V_{i-j}{ }^{n}$ is a velocity component orthogonal to a discontinuity line $l_{i-j}$. The shears on the lines $l_{1-2}$ and $l_{2-3}$ were derived from Figure $2 \mathrm{~b}$ and Equation 6 as follows 
$\gamma_{1-2}=\gamma_{2-3}=1+x \cdot(x-1) /(2-x)$

Thus the total shear during ECAE corresponding to the rigid block analysis is equal to

$\gamma_{S}=\gamma_{1-2}+\gamma_{2-3}=2+2 \cdot x \cdot(x-1) /(2-x)$.

The dependence of total shear after ECAE upon friction factor calculated by ( 8 and 4 ) is shown in Figure $4 b$. The decrease of shear with the increase in friction is clearly visible. When friction factor grows to its maximal value of 2.0 , the reduction in shear of about 0.35 is predicted.

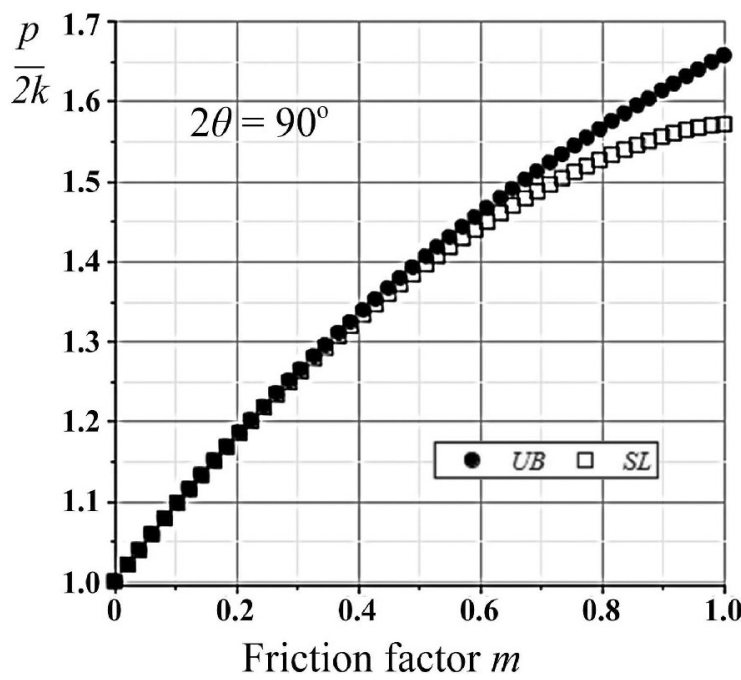

(a)

\section{Discussion}

\subsection{Comparison with slip line analysis}

The slip line analysis of plain-strain deformation of ideal plastic materials at a given external friction is usually discussed in the theory of plasticity as an exact solution. Therefore the comparison of results obtained by rigid block method and results of slip line solution for ECAE is desirable. The slip line analysis of ECAP was pioneered by V. Segal ${ }^{10}$. His slip line field and the hodograph are presented in Figure 5. The dead zone is indicated by number 4 .

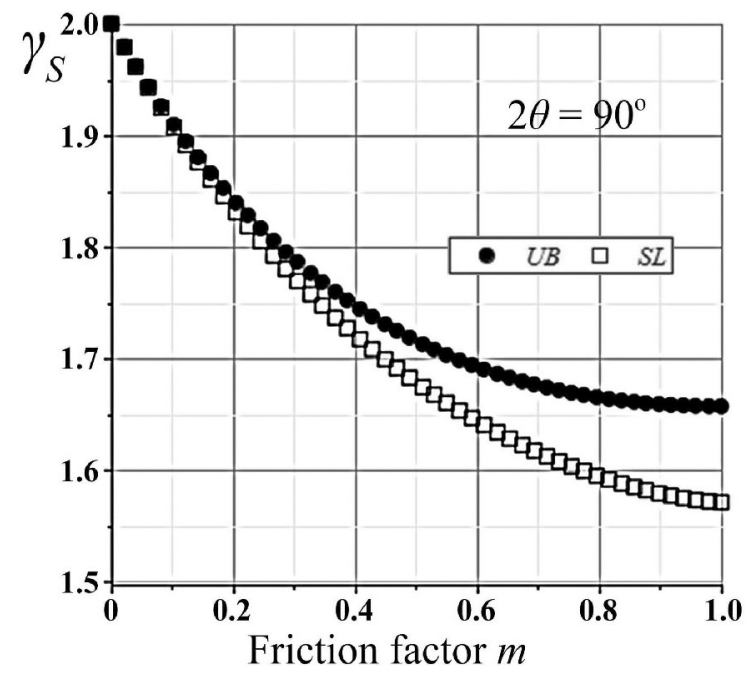

(b)

Figure 4. Relative ECAE pressure $p / 2 k$ (a) and ECAE shear stress $\gamma($ b) at different values of friction factor $m$ computed by rigid blocks analysis (UB) and by slip line analysis (SL).

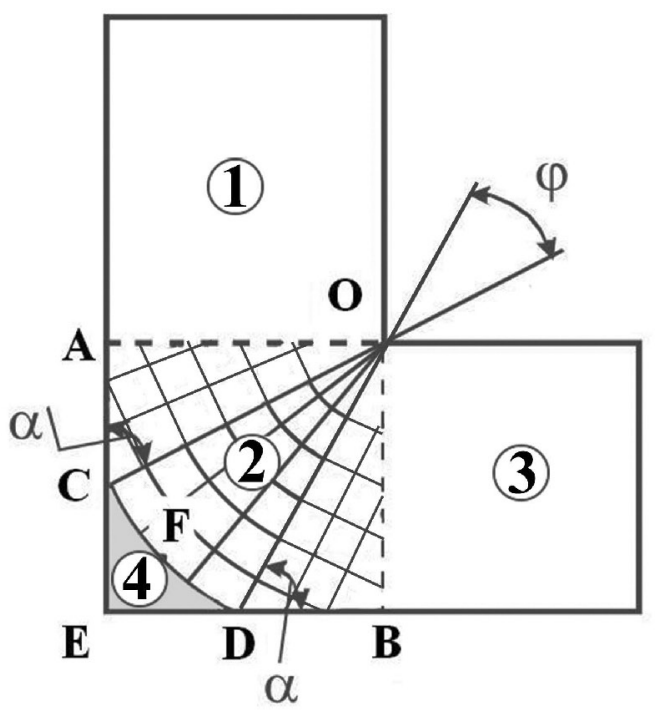

(a)

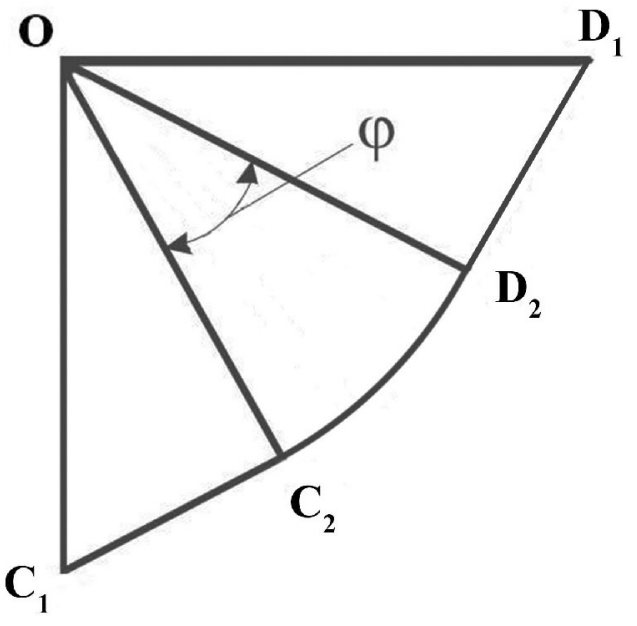

(b)

Figure 5. Slip line field (a) and corresponding hodograph (b) used for ECAE analysis. 
The circular part of the slip line field is characterized by the angle $\varphi$, which is related to the other angle $\alpha$ as

$$
\varphi=2 \alpha-\pi / 2
$$

where angle $\alpha$ is friction dependent and is calculated by the following relationship

$\alpha=\pi / 2-1 / 2 \cdot \arccos (m)$.

Besides this the following dependencies of $\alpha$ can be trigonometrically derived

$\sin (\alpha)=\sqrt{(1+m) / 2}$,

and

$$
\cos (\alpha)=\sqrt{(1-m) / 2}
$$

According to the slip line solution of V. Segal ${ }^{10}$ and taking into account Equations 11 and 12, the total shear during ECAE in a rectangular die can be expressed by the formula

$$
\gamma_{S}=\pi / 2+2 \cdot \sqrt{(1-m) /(1+m)}-\arccos (m) .
$$

The relationship (13) is graphically depicted in Figure $4 \mathrm{~b}$. The total shears obtained by rigid block and slip line analysis are nearly the same at low friction. At the highest friction the total shear derived by the rigid block analysis is only about 0.1 lower then the total shear obtained by the slip line analysis. Thus the difference in shear calculated by two methods is less than $5.5 \%$.

The relative pressure of ECAE in a rectangular die was derived by the slip line technique using equilibrium of forces acting on the rigid blocks ODB and OAC (Figure 5a) and using Hencky's equation for the fan $\mathrm{OCD}^{16}$. The resulting equation, taking into account (11) and (12), has the following form

$p / 2 k=\pi / 2-\arccos (m)+\sqrt{(1+m) \cdot(1-m)}$

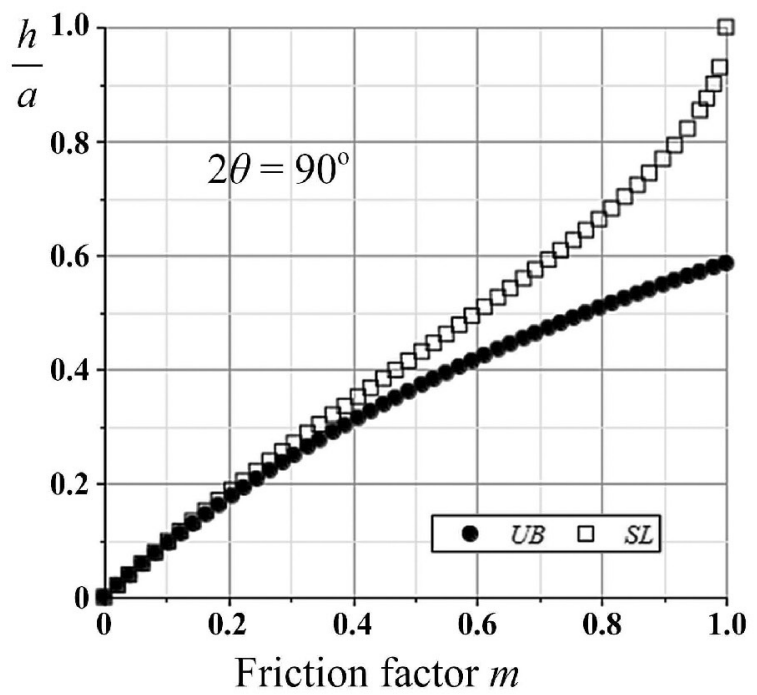

(a)
Graphical representation of the relationship (14) is shown in Figure 4a. The results obtained by rigid block and slip line analysis are similar when friction factor is less than 0.6. At the highest friction factor of 1.0 the overestimation of the relative ECAE pressure by rigid block analysis is less than 0.1 i.e. less than $5.5 \%$.

The relative height of a dead zone $\mathrm{CE}=\mathrm{ED}$ can be estimated from upper bound solution by Formula 4 and calculated from slip line solution by relationship (15)

$h / a=1-\sqrt{(1-m) /(1+m)}$

The results of calculation of the height of dead zone from upper bound and from slip line solutions are shown in Figure 6a. Both analyses predict a substantial growth of a dead zone with the increase in friction. If the friction factor is less than 0.6 , the height of a dead zone obtained from upper bound solution is only slightly lower then the height of this zone predicted by slip line analysis. At larger values of friction factor this difference becomes pronounced.

The relative area $S / a^{2}$ can be considered as another dimensional characteristic of a dead zone. The value of $S /$ $a^{2}$ is estimated from upper bound solution by the following formula obtained from relationship (4)

$S / a^{2}=(h / a)^{2} / 2=2 \cdot(1-1 / \sqrt{1+m})^{2}$.

The relative area of a dead zone calculated from slip line solution is expressed by the formula

$S / a^{2}=1-\sqrt{(1-m) /(1+m)}-(\pi / 2-\arccos (m)) /(1+m)$

The influence of friction factor $m$ on relative area of a dead zone calculated by Equations 16 and 17 is depicted in Figure $6 \mathrm{~b}$. The area of a dead zone grows with the increase in friction. The predicted by upper bound analysis area is slightly smaller then area obtained by slip line analysis when friction factor is below 0.6. At higher values of friction factor this difference becomes well defined.

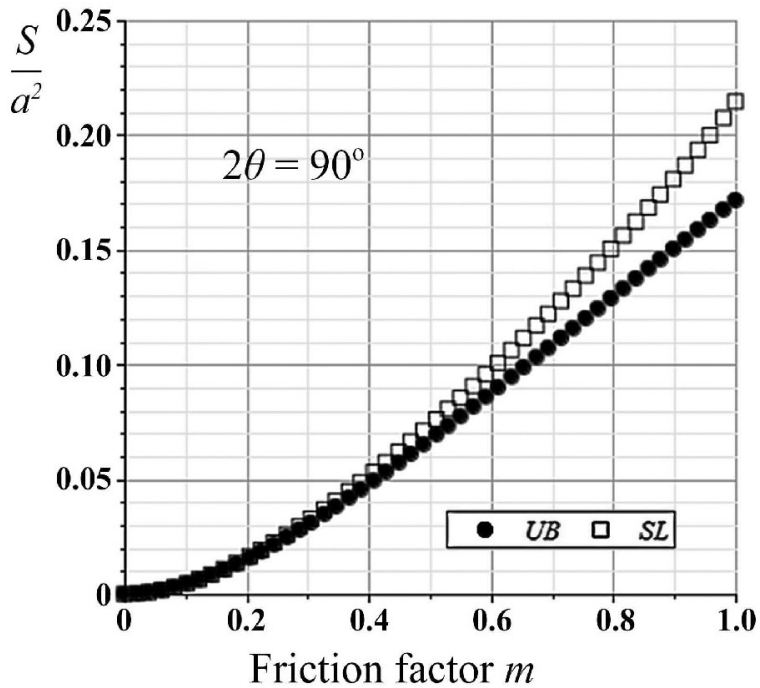

(b)

Figure 6. Relative height of a dead zone (a) and relative area of a dead zone (b) calculated from slip line (SL) and upper bound (UB) solutions. 
It is worth noting that the relative length of the segment EF (Figures 2 and 5), obtained from upper bound solution and from slip line solution, is the same in both cases of study and equals to

$$
l / a=\sqrt{2}-\sqrt{2 \cdot(1+m)}
$$

Thus, the border of a dead zone determined by upper bound analysis is a line tangent to the circular part of the slip line field at the point of its intersection with bisector of the angle $\varphi$ (Figure 5a).

If friction in inlet and outlet channels with the relative length of $l_{i}=l_{1} / a$ and $l_{o}=l_{2} / a$ and back pressure $p_{b}$ are considered, the relative pressure of upper bound analysis can be calculated by the formula

$$
p / 2 k=1+x^{2} /(2-x)+m \cdot(1-x)+2 \cdot\left(m_{i} \cdot l_{i}+m_{o} \cdot l_{o}\right)+p_{b} / 2 k .
$$

Here $m_{i}$ and $m_{o}$ are friction factors in inlet and outlet channels, which can differ from one another and from the friction factor $m$ in deformation zone ${ }^{19}$ Corresponding relationship based on slip line analysis is expressed by the formula

$$
\begin{aligned}
& p / 2 k=\pi / 2-\arccos (m)+\sqrt{(1+m) \cdot(1-m)}+ \\
& +2 \cdot\left(m_{i} \cdot l_{i}+m_{o} \cdot l_{o}\right)+p_{b} / 2 k
\end{aligned}
$$

Summarizing the results of this section, it should be pointed out that both upper bound and slip line analysis predict rise of ECAE pressure and dead zone area and diminishing of the total ECAE shear with the increase in friction. This result additionally indicates that a proper lubrication of ECAE die and extruded sample is an important technological matter. The values of ECAE pressure and ECAE total shear predicted by upper bound and slip line analysis are quite similar. Therefore the developed upper bound approach based on a rigid block model may be used for the analysis of more complex cases and geometries of ECAE process when application of slip line analysis might be difficult.

\subsection{Comparison with experimental data and FEM modeling}

To evaluate the conclusions and relationships of our upper bound analysis we used the results of experiments and finite element simulations of ECAE published by other authors in literature. First of all it should be emphasized that an experimental verification of a theoretical solution based on hypothesis of ideal plasticity of material is a difficult task because of strain-hardening ${ }^{1}$ or softening ${ }^{20}$ of real materials during ECAE. Nevertheless, it seems that the ECAE pressure of low strain-hardening materials like lead or lead based alloys can be evaluated by Formula 3 . For example, an estimation of relative ECAE pressure $p / 2 k$ of $\mathrm{Pb}-4 \% \mathrm{Sb}$ alloy gives the value of 1.45 during the first ECAE pass and the value of 1.69 during the second pass ${ }^{20}$. These values are consistent with relative ECAE pressure calculated by upper bound Formulas 3 and 4 when friction factor is equal to 0.6 and 1.0 respectively. Similar values of friction factor were determined in our ring compression experiments for the frictional plastic contact of lead and low carbon steel $^{21}$.

In the most practical cases essential strain-hardening of materials during ECAE takes place. Therefore the increase of shear strength $k$ during ECAE must be taken into account in the upper bound solution. Moreover, V. Spuskanyuk et al. have correctly reasoned that an ECAE pressure increase due to friction in the inlet and the outlet channels might be comparable with the pressure needed for deformation itself $^{19}$. Therefore for practical calculation of an ECAE pressure an extensive set of data must be provided. This set includes stress-strain relation describing strain-hardening of material, friction factor in both channels and in deformation zone and geometry of the used ECAE die. After extensive literature research we have found only one paper containing nearly full set of data ${ }^{19}$. Despite an ECAE die with rounded outer corner was used in this work, we applied these data for verification of our upper bound solution. The aluminum alloy 6061 billet with the diameter of $13 \mathrm{~mm}$ and $130 \mathrm{~mm}$ in length was annealed at $420{ }^{\circ} \mathrm{C}$ and then used in ECAE experiment. The strain-hardening of 6061 alloy has been described by the equation $k=18.5+117.5 \cdot \gamma^{0.25} \mathrm{MPa}$. Other experiment related data are summarized in Table 1.

The basic Equation 2 was rewritten taking into account both strain-hardening and friction in the channels as

$$
\begin{aligned}
& p \cdot a \cdot V_{1}=k_{1-2} \cdot l_{1-2} \cdot\left[V_{1-2}\right]+k_{2-3} \cdot l_{2-3} \cdot\left[V_{2-3}\right]+ \\
& +k_{2-4} \cdot l_{2-4} \cdot\left[V_{2-4}\right]+m_{1} \cdot k_{1} \cdot l_{A C} \cdot V_{1}+m_{3} \cdot k_{3} \cdot l_{D B} \cdot V_{3}+ \\
& +4 \cdot\left(m_{5} \cdot k_{5} \cdot l_{1} \cdot V_{5}+m_{6} \cdot k_{6} \cdot l_{2} \cdot V_{6}\right) .
\end{aligned}
$$

Here $k_{i}$ is shear strength of a block $i$ after strainhardening, $k_{i-j}$ is shear strength along the common side of blocks $i$ and $j, m_{i}$ is friction factor on the side of block $i$ contacted die wall and $l_{1}, l_{2}$ are lengths of the inlet and outlet channels. It is obviously that $m_{1}=m_{\text {in }}$ and $m_{6}=m_{\text {out }}$. We also assumed that $m_{1}=m_{5}=m_{6}=m_{\text {in }}$. Here $m_{\text {in }}$ and $m_{\text {out }}$ are friction factors related to the inlet and the outlet channel. The shear stress along the common side of two blocks was taken as an average of the shear strengths of these blocks, i.e. $k_{i j}=\left(k_{i}+k_{j}\right) / 2$. The values of accumulated shear and shear strength of individual blocks as well as friction factors are summarized in Table 2.

Calculated by (21) ECAE pressure of $364 \mathrm{MPa}$ is only $7.4 \%$ higher than observed in the experiment. The calculated

Table 1. Data used in experiment and modeling of ECAE and resulting pressures.

\begin{tabular}{ccccccc}
\hline $\boldsymbol{a}, \mathbf{m m}$ & $\boldsymbol{l}_{\boldsymbol{i}}$ & $\boldsymbol{l}_{\boldsymbol{o}}$ & $\boldsymbol{m}_{\text {in }}$ & $\boldsymbol{m}_{\text {out }}$ & $\boldsymbol{p}_{\text {exp }}, \mathbf{M P a}$ & $\boldsymbol{p}_{\text {mod }}, \mathbf{M P a}$ \\
\hline 13 & 2.5 & 1.5 & 0.2 & 0.1 & 339 & 364 \\
\hline
\end{tabular}

Table 2. Shear, shear strength and friction factor related to the rigid blocks and used in upper bound analysis.

\begin{tabular}{lcccccc}
\hline $\begin{array}{c}\text { Block } \\
\text { number }\end{array}$ & $\mathbf{1}$ & $\mathbf{2}$ & $\mathbf{3}$ & $\mathbf{4}$ & $\mathbf{5}$ & $\mathbf{6}$ \\
\hline$m_{i}$ & 0.2 & - & 0.2 & - & 0.2 & 0.1 \\
$\gamma_{\mathrm{i}}$ & 0 & 0.92 & 1.84 & 0 & 0 & 1.84 \\
$k_{i}, \mathrm{MPa}$ & 18.5 & 133.6 & 155.4 & 18.5 & 18.5 & 155.4 \\
\hline
\end{tabular}


pressure coincides with the experimental one if friction factor is taken as 0.16 . It is worthy of note that $35 \%$ of the total ECAE pressure is spent to overcome friction in the inlet and the outlet channels 5 and 6 . Another $5 \%$ of the total pressure is needed to get over friction of deformed zones 1 and 3 over the die wall. The rest $60 \%$ of the total pressure is responsible for the shear deformation during ECAE. Thus friction in the channels is a noticeable factor influencing the total value of ECAE pressure.

The appearance of a dead zone in a sharp outer corner of a rectangular ECAE die was assumed in several theoretical models ${ }^{10,17}$ and observed in experiments with soft materials like plasticine ${ }^{22}$ or wax ${ }^{8}$. From the other side many FEM simulations of ECAP predict rather appearance of gap between deformed billets and die corner ${ }^{22-24}$. This gap may be reduced or fully suppressed by the increase of friction in the outlet channel or by application of back pressure ${ }^{25,26}$. In contrast to this, the appearance of a dead zone during ECAE of an ideal plastic material was found in our earlier FEM simulation $^{27}$. We believe that the appearance of gap or dead zone depends on material rheology as well on friction conditions. This assumption will be verified in our further works. At the moment we can state that an increase of dead zone with rise of friction, as predicted in this work, is confirmed by our finite element analysis ${ }^{27}$, slip line analysis of Segal ${ }^{10}$ and by upper bound analysis of other authors ${ }^{17}$.

The results of investigations of friction influence on resulting ECAE shear are also ambiguous. Some authors based on FEM simulation and experiments argue that total ECAE shear grows with the rise in friction factor ${ }^{28}$. Other authors did not find in their FEM simulation any noticeable effect of friction on resulting ECAE shear ${ }^{15}$. A substantial decrease of total shear with the increase in friction factor was resulted from our earlier FEM simulation of ECAE of an ideal plastic material ${ }^{27}$. In general, ECAE shear diminishes with grow of zone of intensive deformation. This zone corresponds to the fan part of slip line field (Figure 5) or to the width of block 2 in our upper bound model (Figure 2).
Thus at the present time a generally recognized opinion about the influence of friction on resulting ECAE shear does not exist. However, the decrease of shear with the increase in friction, as found in the present paper, is confirmed by our FEM simulation ${ }^{27}$, slip line analysis of Segal ${ }^{10}$ and upper bound analysis based on a continuous admissible velocity field of other researchers ${ }^{17}$.

\section{Conclusions}

In the present paper the upper bound analysis and rigid block model were successfully applied to theoretical modeling of pressure and shear during Equal Channel Angular Extrusion in a rectangular die. The physical simulation by plasticine was used to highlight the peculiarities of material flow during ECAE and to identify the deformation zones. Particularly the appearance of a dead zone in a die sharp corner was confirmed.

The upper bound analysis predicted that an increase in friction leads to rise of a dead zone area and to diminishing of the total ECAE shear. This result additionally indicates that a proper lubrication of ECAE die and extruded sample is an important technological matter. The results obtained by upper bound analysis are qualitatively and quantitatively similar to the results obtained from slip line analysis of ECAE. Therefore we believe that the developed upper bound approach based on a rigid block model may be used for analytical analysis of more complex cases and geometries of ECAE process, when application of slip line analysis might be difficult.

Comparison with experimental data published in the literature has shown that the obtained upper bound relationships can be used in practice for estimation of ECAE pressure if strain-hardening of material and friction in the die channels are taken into account. Upper bound predictions of the appearance of a dead zone and the decrease in shear with the rise in friction are more controversial, but confirmed by our FEM simulation, slip line analysis and upper bound analysis of other authors based on continuous velocity field.

\section{References}

1. Valiev RZ and Langdon TG. Principles of equal-channel angular pressing as a processing tool for grain refinement. Progress in Materials Science. 2006; 51 (7):881-982. http:// dx.doi.org/10.1016/j.pmatsci.2006.02.003

2. Poggiali FSJ, Figueiredo RB, Aguilar MTP and Cetlin PR. Grain refinement of commercial purity magnesium processed by ECAP (Equal Channel Angular Pressing). Materials Research. 2012; 15(2):312-316. http://dx.doi.org/10.1590/ S1516-14392012005000022

3. Cardoso KR, Travessa DN, Jorge AM and Botta WJ. Microstructure evolution of AA7050 Al alloy during equalchannel angular pressing. Materials Research. 2012; 15(5):732738. http://dx.doi.org/10.1590/S1516-14392012005000105

4. Figueiredo RB and Langdon TG. Fabricating ultrafine-grained materials through the application of severe plastic deformation: a review of developments in Brazil. Journal of Materials Research and Technology. 2012; (1):55-62. http://dx.doi. org/10.1016/j.jmrt.2013.04.001

5. Altan BS, Purcek G and Miskioglu I. An upper-bound analysis for equal-channel angular extrusion. Journal of Materials Processing Technology. 2005; 168(1):137-146. http://dx.doi. org/10.1016/j.jmatprotec.2004.11.010

6. Dumoulin S, Roven HJ, Werenskiold JC and Valberg HC. Finite element modeling of equal channel angular pressing: Effect of material properties, friction and die geometry. Materials Science and Engineering A. 2005; 410-411(1):248-251. http:// dx.doi.org/10.1016/j.msea.2005.08.103

7. Manna R, Agrawal P, Joshi S, Mudda BK, Mukhopadhyay NK and Sastry GVS. Physical modeling of equal channel angular pressing using plasticine. Scripta Materialia. 2005; 53(12):1357-1361. http://dx.doi.org/10.1016/j. scriptamat.2005.08.031

8. Rosochowski A and Olejnik L. Numerical and physical modelling of plastic deformation in 2-turn equal channel angular extrusion. Journal of Materials Processing Technology. 2002; 125-126(1):309-316. http://dx.doi.org/10.1016/S09240136(02)00339-4 
9. Perig AV, Laptev AM, Golodenko NN, Erfort YA and Bondarenko EA. Equal channel angular extrusion of soft solids. Materials Science and Engineering A. 2010; 527(16-17):37693776. http://dx.doi.org/10.1016/j.msea.2010.03.04

10. Segal VM. Slip line solutions, deformation mode and loading history during equal channel angular extrusion. Materials Science and Engineering A. 2003; 345(1-2):36-46. http:// dx.doi.org/10.1016/S0921-5093(02)00258-7

11. Eivani AR and Karimi Taheri A. An upper bound solution of ECAE process with outer curved corner. Journal of Materials Processing Technology. 2007; 182(1-3):555-563. http://dx.doi. org/10.1016/j.jmatprotec.2006.09.021

12. Reihanian M, Ebrahimi R and Moshksar MM. Upper-bound analysis of equal channel angular extrusion using linear and rotational velocity fields. Materials and Design. 2009; 30 (1):28-34. http://dx.doi.org/10.1016/j.matdes.2008.4.059

13. Pérez CJL and Luri R. Study of the ECAE process by the upper bound method considering the correct die design. Mechanics of Materials. 2008; 40(8):617-628. http://dx.doi.org/10.1016/j. mechmat.2008.02.003

14. Milind TR and Date PP. Analytical and finite element modeling of strain generated in equal channel angular extrusion. International Journal of Mechanical Sciences. 2012; 56(1):2634. http://dx.doi.org/10.1016/j.ijmecsci.2011.12.002

15. Xu S, Zhao G, Ma X and Ren G. Finite element analysis and optimization of equal channel angular pressing for producing ultra-fine grained materials. Journal of Materials Processing Technology. 2007; 184(1-3):209-216. http://dx.doi. org/10.1016/j.jmatprotec.2006.11.025

16. Johnson W, Kudo H. The mechanics of metal extrusion. Manchester University Press; 1962.

17. Eivani AR and Karimi Taheri A. The effect of dead metal zone formation on strain and extrusion force during equal channel angular extrusion. Computational Materials Science. 2008; 42(1):14-20. http://dx.doi.org/10.1016/j. commatsci.2007.06.001

18. American Society for Metals Handbook. Forming and Forging. 9th ed. ASM International; 1996.

19. Spuskanyuk VZ, Gangalo AN, Davidenko AA and Kovalenko IM. An upper bound solution of equal channel angular extrusion and equal channel angular hydroextrusion processes. Materials
Working by Pressure. 2009; 1 (20):50-56. http://www.dgma. donetsk.ua/science_public/omd/1(20)2009.pdf

20. Figueiredo RB, De Moraes Costa AL, Andrade MS, Aguilar MTP and Cetlin PR. Microstructure and mechanical properties of $\mathrm{Pb}-4 \% \mathrm{Sb}$ alloy processed by equal channel angular pressing. Materials Research. 2006; 9(1):101-106. http://dx.doi. org/10.1590/S1516-14392006000100019

21. Perig AV. Improvement of processes of angular pressing on the basis of modeling of equal channel materials plastic flow. [Dissertation]. Kramatorsk: Donbass State Engineering Academy; 2011.

22. Balasundar I, Sudhakara Rao M, Raghu T. Equal channel angular pressing die to extrude a variety of materials. Materials and Design. 2009; 30(4):1050-1059. http://dx.doi. org/10.1016/j.matdes.2008.06.057

23. Li S, Bourke MAM, Beyerlein IJ, Alexander DJ and Clausen B. Finite element analysis of the plastic deformation zone and working load in equal channel angular extrusion. Materials Science and Engineering A. 2004; 382(1-2):217-236. http:// dx.doi.org/10.1016/j.msea.2004.04.067

24. Yoon SC and Kim HS. Finite element analysis of the effect of the inner corner angle in equal channel angular pressing. Materials Science and Engineering A. 2008; 490(1-2):438-444. http://dx.doi.org/10.1016/j.msea.2008.01.066

25. Lapovok IYe. The role of back-pressure in equal channel angular extrusion. Journal of Materials Science. 2005; 40(2):341-346. http://dx.doi.org/10.1007/s10853-005-6088-0

26. Son IH, Lee JH and Im YT. Finite element investigation of equal channel angular extrusion with back pressure. Journal of Materials Processing Technology. 2006; 171(3):480-487. http://dx.doi.org/10.1016/j.jmatprotec.2005.11.001

27. Perig AV, Kakavas PA, Anyfantis KN and Laptev AM. Mechanics of the equal channel angular extrusion. In: Proceedings of the XXXVI International Summer School "Advanced Problems in Mechanics"; 2008; St. Petersburg. St. Petersburg; 2008. p. 513-520. Available from: <http://apmconf.spb.ru/2008/apm2008_proceedings.pdf >.

28. Bowen JR, Gholinia A, Robetts SM and Prangnell PB. Analysis of the billet deformation behaviour in equal channel angular extrusion. Materials Science and Engineering A. 2000; 287(1):87-99. http://dx.doi.org/10.1016/S09215093(00)00834-0 